\title{
Culling Tomatoes with External Symptoms of Irregular Ripening Is of Limited Benefit
}

\author{
Charles A. Powell and Peter J. Stoffella \\ Agricultural Research and Education Center, Institute of Food and Agricultural \\ Sciences, University of Florida, Box 248, Fort Pierce, FL 34954
}

Additional index words. Lycopersicon esculentum, Bemisia tabaci, sweet potato whitefly

\begin{abstract}
Mature-green and mature-red tomato (Lycopersicon esculentum Mill.) fruit were harvested from spring- and fall-grown plants infested with sweet potato whitefly (SPWF; Bemisia tabaci Gennadins). The mature-green fruit were either ripened at 20 to $22 \mathrm{C}$ or cold-stored at 10 to $13 \mathrm{C}$ for 3 weeks and then were allowed to ripen at 20 to $22 \mathrm{C}$. There was no significant difference in the appearance of either external or internal tomato irregular ripening (TIR) symptoms between the two storage-ripening regimes or in the appearance of internal TIR symptoms among the two storage regimes and vine-ripened tomatoes. Thus, removing the tomatoes from the SPWF during ripening does not reduce TIR symptoms. About half of the mature-green tomatoes, ripened with or without cold storage (10 to 13C), developed no external TIR symptoms, but about half of these tomatoes had internal TIR symptoms. About one-third of the tomatoes developed external symptoms during ripening, but these symptoms disappeared after ripening was complete. A high percentage $(\mathbf{7 1 \%}$ ) of these tomatoes with external symptoms also had internal symptoms. The remaining tomatoes developed external TIR that did not disappear, and almost all of these tomatoes had internal symptoms. These data suggest that culling tomatoes that develop external TIR during ripening will reduce but not eliminate tomatoes with internal TIR from the fresh-fruit market.
\end{abstract}

Tomato (Lycopersicon esculentum Mill.) irregular ripening (TIR) is a disorder associated with sweet potato whitefly (SPWF; Maynard and Cantliffe, 1989) feeding. Symptoms, which are limited to fruit, are external and internal. The external symptoms of redripe fruit include green, white, or pink streaks or blotches (irregular ripening patterns) on the surface of otherwise ripe fruit. Sometimes a white or yellow star-like discoloration appears at the blossom end of the fruit. In the interior, affected fruit appear white or yellow on the fruit walls. In severe cases, the entire interior of the fruit appears white. The external and internal symptoms make the fruit less desirable in appearance and, presumably, flavor. Most fruit with external symptoms also have internal symptoms, but many fruit with internal symptoms do not have external symptoms (unpublished data).

Tomatoes normally are harvested when mature green, before the appearance of TIR symptoms, and are allowed to ripen at room temperature or in ripening rooms with a controlled ethylene application. To our knowledge, information on how ripening affects TIR symptom development is not available. In this

Received for publication 25 Apr. 1994. Accepted for publication 12 Nov. 1994. Florida Agricultural Expt. Station Journal Series no. R-03755. We thank Mike Fleming and Jack Cordy for their technical assistance. The cost of publishing this paper was defrayed in part by the payment of page charges. Under postal regulations, this paper therefore must be hereby marked advertisement solely to indicate this fact. study, we compare two different ripening protocols for their effect on development of external and internal TIR symptoms and examine the associations between these two types of symptoms.

\section{Materials and Methods}

'Sunny' tomato transplants (5 weeks old) were planted on 15 Sept. 1992 and 2 Mar. 1993 (fall and spring seasons, respectively), at the Agricultural Research and Education Center, Fort Pierce, Fla. Soil-type classification, bed preparation, disease control, and fertilization practices were as described by Powell and Stoffella (1993). In 1992, the experimental area consisted of four rows, each $60 \mathrm{~m}$ long and serving as a replication. In 1993, we used eight rows, each $30.5 \mathrm{~m}$ long with each two rows serving as a replication. Transplants in the rows were spaced $61 \mathrm{~cm}$ apart, equivalent to 7687 plants/ha. Five weeks after transplanting, SPWF were introduced into the plot by placing 20 pots ( 3.7 liters) containing infested tomato plants into each row at 3-m intervals. These plants had been SPWF-infested in the greenhouse. No insecticides were applied to the experimental area. SPWF populations were monitored weekly using three, $7.5 \times 7.5-\mathrm{cm}$, yellow, sticky boards (Great Lakes; IPM, Vestaburg, Mich.) per row (Powell and Stoffella, 1993).

On 9 Dec. 1992 and 2 June 1993 (fall and spring experiments, respectively), 100 redripe tomatoes were harvested and cut to assess the extent of external and internal TIR. One week later, 200 mature-green tomatoes were picked at random from each replication. Tomatoes were judged to be mature by a slight blush of pink color on the fruit. Half of the tomatoes (100 fruit from each replication) were stored in an air-conditioned room that was maintained at 20 to $22 \mathrm{C}$. The other 400 fruit were stored in a room at 10 to $13 \mathrm{C}$. Each tomato was evaluated every 3 days for external TIR symptoms. When a fruit became completely red on the exterior (red ripe), it was sliced in half equatorially, and internal TIR symptoms were recorded. After 20 days, when the tomatoes at 20 to $22 \mathrm{C}$ were either ripe or starting to decay, the remaining tomatoes were cut to assess TIR. Then, the tomatoes that had been stored at 10 to $13 \mathrm{C}$ (none of which had ripened) were transferred to the air-conditioned room ( 20 to $22 \mathrm{C}$ ) and monitored every 3 days for 2 weeks for external and internal TIR symptoms as previously described. Tomatoes were divided into three categories with respect to external TIR symptoms: 1) ripened without ever exhibiting external TIR, 2) had external TIR at the conclusion of the experiment, and 3) developed external TIR symptoms during ripening with symptoms disappearing after fruit reached the red-ripe stage.

A split-block experimental design was used with ripening temperature as the main block, each replicated four times. Number of fruit with external and internal TIR symptoms were converted to percentages. Analyses of variance (ANOVA) were performed on arcsin square-root-transformed data. The main effects of ripening temperature were separated by an F test. An ANOVA was conducted for each experiment.

\section{Results and Discussion}

SPWF densities in the spring and fall experiments started low and increased throughout the experiment. Curves resembled those previously reported (Powell and Stoffella, 1990). The week before harvest, the mean

Table 1. Development of external and internal tomato irregular ripening (TIR) symptoms on tomatoes harvested at mature green and ripened at 20 to $22 \mathrm{C}$ or 10 to $13 \mathrm{C}$.

\begin{tabular}{lcc}
\hline $\begin{array}{l}\text { Ripening } \\
\text { temp } \\
\left({ }^{\circ} \mathrm{C}\right)\end{array}$ & \multicolumn{2}{c}{ Fruit with TIR symptoms } \\
\cline { 2 - 3 } & $\begin{array}{c}\text { External } \\
(\%)\end{array}$ & $\begin{array}{c}\text { Internal }^{\mathrm{x}} \\
(\%)\end{array}$ \\
\hline & Fall 1992 \\
20 to 22 & 28.7 & 73.0 \\
10 to 13 & 50.5 & 75.3 \\
& Spring 1993 \\
20 to 22 & 45.0 & \\
10 to 13 & 50.0 & 59.0 \\
\end{tabular}

${ }^{2}$ Mature-green fruit were maintained for 20 days at 20 to $22 \mathrm{C}$ or for 21 days at 10 to $13 \mathrm{C}$ followed by 14 days at 20 to $22 \mathrm{C}$.

${ }^{y}$ Fruit that exhibited external TIR at some point during ripening. Means were not significantly different at $P \leq 0.05$ between ripening temperatures or seasons.

${ }^{x}$ Fruit that displayed internal TIR at the conclusion of the experiment. Means were not significantly different between ripening regimes or seasons at $P$ $\leq 0.05$.

HortScience, Vol. 30(2), April 1995 
SPWF population counts were 37 and 72 flies per sticky board for the fall and spring experiments, respectively. These values are about two- to five-times higher than those reported in previous years (Powell and Stoffella, 1990, 1993). One week before the harvest of maturegreen fruit, red-ripe tomatoes examined for internal symptoms had a mean internal TIR of $68 \%$ in fall and $62 \%$ in spring. There were no external symptoms on the red-ripe tomatoes, but there was some external TIR on nonharvested, partially ripe tomatoes.

Removing fruit from the SPWF influence by harvesting it mature-green and allowing the fruit to ripen either with or without cold storage did not reduce, and possibly even exacerbated, TIR symptoms. The percentages of ripe fruit with either external or internal TIR were similar for the two storage temperatures in fall and spring $(P \leq 0.05)$ (Table 1$)$. However, in all cases, the percentage of external (29\% to $50 \%$ ) and internal (59\% to $75 \%$ ) TIR was unacceptably high for fresh-market fruit. These percentages of fruit with symptoms were higher than those reported in previous experiments (Powell and Stoffella, 1993). Although SPWF were introduced into the plots, the levels were similar to those commonly occurring in natural infestations (Powell and Stoffella, 1993). The high percentage of symptoms confirms that the TIR disorder has a major adverse effect on fresh-market tomatoes.
There was a higher incidence of internal TIR in fruit that had external symptoms (Table 2). Many of the fruit that exhibited external symptoms at some time during ripening recovered from the symptoms and appeared normal when they reached the red-ripe stage, but these fruit had a mean internal TIR of $71 \%$. This result indicates that fruit displaying external TIR symptoms during ripening should be culled. However, many fruit that did not have external TIR symptoms had internal symptoms (48\%). Therefore, culling fruit with external TIR during ripening will not eliminate all fruit with internal symptoms.

\section{Literature Cited}

Maynard, D.N. and D.J. Cantliffe. 1989. Squash silverleaf and tomato irregular ripening: New vegetable disorders in Florida. Florida Coop. Ext. Serv. Inst. of Food and Agricultural Sciences VC-37.

Powell, C.A. and P.J. Stoffella. 1990. Endosulfan and silver reflective mulch effects on sweet potato whitefly populations and yields of zucchini squash and tomatoes. Proc. Fla. State Hort. Soc. 103:117-119.

Powell, C.A. and P.J. Stoffella. 1993. Influence of endosulfan sprays and aluminum mulch on sweetpotato whitefly disorders of zucchini squash and tomatoes. J. Prod. Agr. 6:118-121.

Table 2. Relationship between external and internal tomato irregular ripening (TIR) symptoms.

\begin{tabular}{|c|c|c|c|c|c|c|}
\hline \multirow{3}{*}{$\begin{array}{l}\text { External TIR fruit } \\
\text { symptom category }\end{array}$} & \multicolumn{3}{|c|}{$\begin{array}{l}\text { Fruit each category } \\
(\%)\end{array}$} & \multicolumn{3}{|c|}{$\begin{array}{l}\text { Fruit with internal TIR } \\
(\%)\end{array}$} \\
\hline & \multicolumn{3}{|c|}{ Ripened at $\left({ }^{\circ} \mathrm{C}\right)$} & \multicolumn{3}{|c|}{ Ripened at $\left({ }^{\circ} \mathrm{C}\right)$} \\
\hline & 20 to $22^{z}$ & 10 to $13^{y}$ & Mean & 20 to $22^{z}$ & 10 to $13^{y}$ & Mean \\
\hline External TIR ${ }^{\mathrm{x}}$ & 16.5 & 11.5 & 14.0 & 91.0 & 100.0 & 95.5 \\
\hline External TIR ${ }^{\mathrm{w}}$ & 28.5 & 38.5 & 33.5 & 73.0 & 69.0 & 71.0 \\
\hline None $^{v}$ & 55.0 & 50.0 & 52.5 & 43.0 & 53.0 & 48.0 \\
\hline
\end{tabular}

${ }^{\mathrm{z}}$ Mature-green fruit were maintained for 20 days at 20 to 22C. Means were not significantly different at $P$ $=0.05$ between the two storage regimes.

${ }^{\mathrm{y}}$ Mature-green fruit were held at 10 to $13 \mathrm{C}$ followed by 14 days at 20 to $22 \mathrm{C}$. Means were not significantly different at $P=0.05$ between the two storage regimes.

xTomato fruit exhibited external TIR symptoms at the conclusion of the experiment (red-ripe stage).

wTomato fruit exhibited external TIR symptoms at some point during the ripening process but disappeared, and fruit looked normal on the exterior when reaching the red-ripe stage.

vTomato fruit ripened normally without exhibiting any external TIR symptoms at the red-ripe stage. 